\title{
Inclusive Learning Resource Design Based on Universal Design for Learning-Case Study of Mechanics of Materials Course
}

\author{
Yingwei Yun ${ }^{1,}$, , Seong-kyum Kim², Fengli Fan $^{1}$ \\ ${ }^{1}$ Civil Engineering School, Luoyang Institute of Science \& Technology, Luoyang, China \\ ${ }^{2}$ Research Institute for Mega Structures, Korea University, Seoul, Korea \\ Email address: \\ Yyw007@aliyun.com (Yingwei Yun), envylife@korea.ac.kr (Seong-kyum Kim), fanfengli1981@163.com (Fengli Fan) \\ ${ }^{*}$ Corresponding author
}

\section{To cite this article:}

Yingwei Yun, Seong-kyum Kim, Fengli Fan. Inclusive Learning Resource Design Based on Universal Design for Learning - Case Study of Mechanics of Materials Course. Education Journal. Vol. 7, No. 4, 2018, pp. 75-82. doi: 10.11648/j.edu.20180704.11

Received: May 2, 2018; Accepted: September 18, 2018; Published: October 18, 2018

\begin{abstract}
Universal design for learning is an effective means to improve students' learning effects and to improve lecturers' instructional design, which may benefit improving teaching quality of higher education under new situation in China. This paper carried out the learning resource design according to UDL theory by setting mechanics of material subject as an example, which aims to integrate the main principles of UDL theory into inclusive course design. By applying UDL theory, ICARE model and novel technical means, the course design details have been expounded from teaching representation means for lecturers, action and expression means for learners, and engagement means for learners, respectively. The benefits of integrating UDL into course design for lectures, learners and daily teaching activities are analyzed as well. The work in this paper would have a great significance to promote the integration of UDL theory, advanced teaching philosophy, and novel technical means into learning course design to improve teaching efficiency of lecturers and learning outcome of learners.
\end{abstract}

Keywords: Universal Design for Learning, Learning Resource Design, Higher Education, Material of Mechanics, ICARE Model

\section{Introduction}

With the deep development of integration of global economy, the international communication in higher education field is rapidly increasing all over the world. How to break the learning barriers such as cultural differences, language issues and so forth faced by college students to realize educational equality has become a key issue encountered by educators and governors.

According to the Journal of Postsecondary Education and Disability, eleven percent of undergraduates report some type of disability - and the proportions have swapped such that the majority of disabilities are now non-apparent (e.g., mental, emotional, psychiatric condition/depression, ADHD, specific learning disabilities/dyslexia), compared to more apparent disabilities (e.g. mobility impairment). Meanwhile, between sixty and eighty percent of students with disabilities don't actually contact campus university services for "official" accommodation requests/reporting-which means many students in your classrooms may fall in this category without your knowledge. This is also an issue of social justice. By putting disability and access considerations at the center of our teaching, we join efforts to make higher education accessible to all of our students.

Universal Design for Learning (UDL) is exactly an ideal means to solve this issue. UDL gives all individuals equal opportunities to learn and provides a blueprint for creating instructional goals, methods, materials, and assessments that work for everyone- not a single, one-size-fits-all solution, but rather flexible approaches that can be customized and adjusted for individual needs [1].

In this paper, the course "Mechanics of materials" is set as a case study to develop its learning resources according to UDL principles. The learning resource was designed according to the three main principles of UDL, which aim to meet the preferences of diverse learners including the 
international students and students with learning disabilities. Novel technical means such as video, animation and QR code are included in the resource to provide multiple means of representation. Additionally, different formats of resource are delivered such as power point, pdf and online resources those are convenient for study on laptop or mobile phone accessing internet. The learning outcomes of this course will be assessed by class practice, homework and final exam. Feedback and questions can be upload online asynchronously as well after class.

\section{UDL and Design Strategies}

\subsection{Fundamental Theory of UDL}

UDL is an educational framework based on research in the learning sciences, including cognitive neuroscience that guides the development of flexible learning environments that can accommodate individual learning differences [2].
UDL aims to improve and optimize teaching and learning for all people based on scientific insights into how humans learn [3]. The goal of UDL is to eliminate the barriers from the learning environment [4].

UDL is a set of principles that guide the design of inclusive classroom instruction and accessible course materials. As shown in Figure 1, the three principles of UDL are: multiple means of representation that give learners a variety of ways to acquire information and build knowledge; multiple means of action and expression that provide learners alternatives to demonstrate what they have learned; and multiple means of engagement that tap into learners' interests, challenge them appropriately, and motivate them to learn [5]. Many researchers have demonstrated that application of UDL on postsecondary education courses had a positive impact on students' academic performance [6-8], and supported better access, participation and progress $[2,9,10]$. Universal Design for Learning
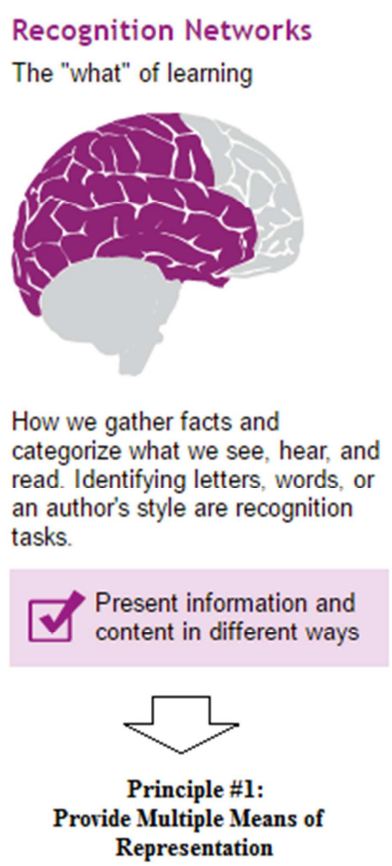

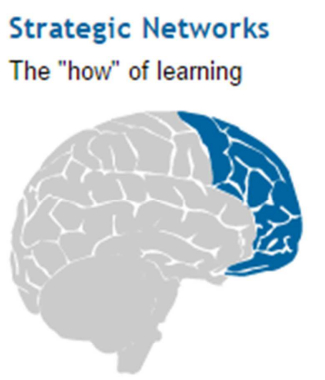

Planning and performing tasks. How we organize and express our ideas. Writing an essay or solving a math problem are strategic tasks.

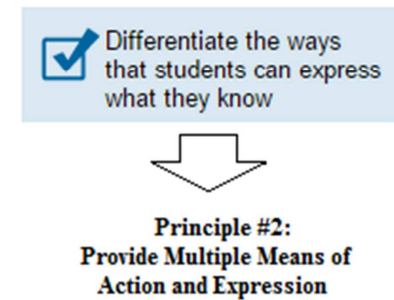

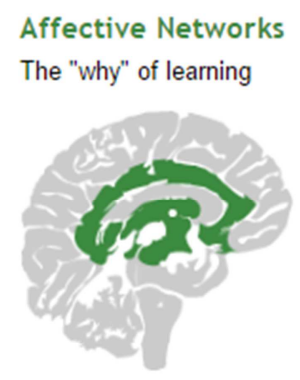

How learners get engaged and stay motivated. How they are challenged, excited, or interested. These are affective dimensions.

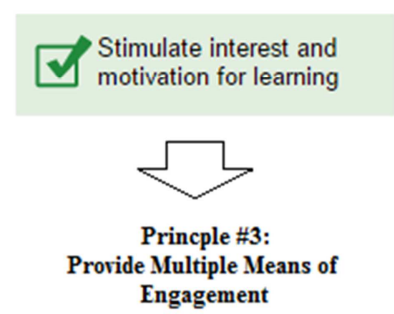

Figure 1. Three principles of UDL and their relationships with different parts of human brain.

\subsection{Outline of the Designed Course}

Mechanics of materials, also referred to strength of materials, mechanics of deformable bodies, aims to study the strength, stiffness and stability of deformable body on which external forces act. Mechanics of materials, one branch of solid mechanics, is one of the important special compulsory curricula for most engineering undergraduates, which is one key prerequisite curriculum for many special courses in diverse disciplines such as Structural Analysis and Design, Foundation Engineering in civil engineering, mechanical design in Mechanical engineering. Almost all the sub-disciplines within civil engineering area, such as structural engineering, geotechnical engineering, mineral engineering, pipeline engineering or transportation engineering should include Mechanics of materials as one compulsory knowledge.

The learning outcomes of this course are: the good command of mechanical behaviors of the six basic deformable styles; proficiency in strength checking, deformation calculation and stability checking of engineering members; good skills in utilizing superposition method and virtual displacement method to solve engineering problems; preliminary understanding combined deformation. 


\subsection{Applied Design Model}

Due to the strict logic of mechanics of materials, content of learning resource should be provided in an organized and logical fashion to support students leaning. ICARE model is such an instructional design model to satisfy the requirement, which was put forward by Hoffman and Ritchie in 1998. Then ICARE model is suitable for designing the learning resource with strict logic. ICARE stands for Introduction, Content or connect, Apply, Reflect, and Extend [11]. In the introduction part, the unit or module is introduced including context, objectives, and/or pre-requisites required. Content section introduces necessary facts, concepts, principles, and/or processes to students or provides them with scaffolds allowing them to discover these for themselves, which is the core part of the unit or module. Apply asks students to apply lesson content in solving practice issues. Reflect part ask students to spend some time to reflect upon what they have learned as they have moved from Connect to Apply section of the unit or module. Activities or questions here should help students apply metacognitive process as they articulate what they have experienced or learned. Extend section offers opportunities to individualize learning experience with additional, optional learning material and activities. One point should be noted is that ICARE model is suitable for individual section content design in this course separately, such as bending normal stress derivation and application section, virtual displacement principle section and so forth, but not fit for the whole course design, as the strict logic relation does not exist all the time.

\section{Learning Resource Design by UDL}

Among the six basic deformable styles in mechanics of materials, bending is the most commonly used one in engineering practice such as in beam design (reinforced or steel), bridge design even in foundation design, aseismic design of buildings. Moreover, the bending normal formula is not only one of the emphases, but also one of difficult parts in this course. According to teaching experiences from lecturers in this curriculum, many of the students have difficulties in understanding the derivation process of the bending normal stress formula, which may obstruct the further application of the formula in solving problems. Many efforts have been made in the last few years to make this module more accessible to diverse students, but the expected effects did not achieve. In order to eliminate the learning barriers in this module and to make it more accessible to diverse learners, as an example, this module will be designed according to the main principles of UDL. Based on the main theory of UDL, the learning resource is designed to assist students to learn more accessibly. The main points are expounded below in details.

\subsection{Multiple Means of Representation}

Firstly, the learning resource has been provided by different document styles, ppt, pdf and jpg formats which give diverse options to students with different preferences. Secondly, pre-requisite knowledge would be briefly reviewed at the beginning of the module that may remove the possible obstacles in the following contents. Thirdly, necessary animations and relevant graphs have been supplemented in the module to provide diverse options for learners to understand the most difficult part in this module. Fourthly, relevant instructional videos are provided for learners to study after class. Finally, asynchronous on line learning resource are available to diverse learners after class, and the online resource is linked with corresponding content by relevant QR code which is convenient for student to search and learn. Additionally, as the potential learners may include some international students or native students who expect to attend bilingual teaching course, which may help them to adapt themselves into the future study oversea delivered by complete English. So learning resource in English is also prepared for their reference.

\subsection{Multiple Means of Action and Expression}

Multiple means of action and expression should be provided to meet the diverse needs to demonstrate their study effects. The assessment effects of traditional written exam are limited except its easy operability. Other novel assessment methods such as oral test, group collaboration plus presentation and so forth ought to be attempted to meet the diverse learners. Considering the Mechanics of materials module, group co-work plus presentation is a good means to assess students. Several studies have showed that collaboration among students can have a very positive impact both on student engagement and student retention [12-15]. One old Chinese saying is "In a party of three there must be one whom I can learn from", which indicates that group members can learn from each other to improve themselves by collaboration. By this novel means, students can not only study and practice more by group collaboration, but also they would be much more interested and confident in this module study. In addition, online discussion boards can be set up using the online learning environment and these can be a valuable tool for students who may not be able to attend campus outside of class hours.

\subsection{Multiple Means of Engagement}

Firstly, at the introduction part, some background practice video relevant with module contents would be provided for students to watch in class, which aims to attract students' attention and help them to understand the importance of module content and its application. Secondly, convenient QR code technique has been applied throughout the learning resource, which will motivate and facilitate students to learn by this novel technological means. Thirdly, online resource can be learned without time and location limit, and is convenient to be learned by mobile phone, IPAD or other portable electronic device with internet. This kind of "movable class" will interest student learning. Finally, Feedback for the module content is easy to transfer to 
lecturer via online message function, and individual questions will be concerned and replied by lecturer in time. This individual tuition will also greatly motivate learner's study interest.

\section{Analysis and Reflection}

How to integrate UDL theory into learning resource design to make lessons more accessible to diverse students is one key point in application. By applying UDL theory to develop this learning resource on Mechanics of materials module, analysis and measures can be drawn from three aspects below.

\subsection{UDL and Lecturer's Instructional Design}

There is no one perfect representation means that may be optimal for all potential learners. Therefore, it is essential to provide optional representation means as learners differ in the ways perceiving and understanding knowledge that is taught to them. By considering the learning need of diverse students, learning resource design aims to cover all the needs of diverse students by using multiple means of representation such as PPT, audio, video, on-line course or black board writing, which are expected to provide equal opportunities to access module learning. In this learning resource design, background video, examples teaching video, relevant animations, on line resource and $\mathrm{QR}$ code technique are included in this learning resource. Moreover, bilingual learning resources with different file formats (PPT, pdf and Jpg) are given as well. Some print screens of learning resource with QR code, animation and bilingual options are shown in Figure 2. Figure 3 aiming to teach how to scan $\mathrm{QR}$ code to achieve relevant video by mobile phone accessing internet. As the QR code is a convenient tool to link relevant video resource, graphs or website with the module while you need not to download them on your electronic device. Utilization of QR code technique can save downloading time and the hard disk space (some of the videos are very big, even hundreds of Megabytes, downloading need much time depending on your device and internet. Much worse is that some of videos are forbidden to download in some website, such as YouTube, Youku), but also can avoid repeated downloading when using different device.

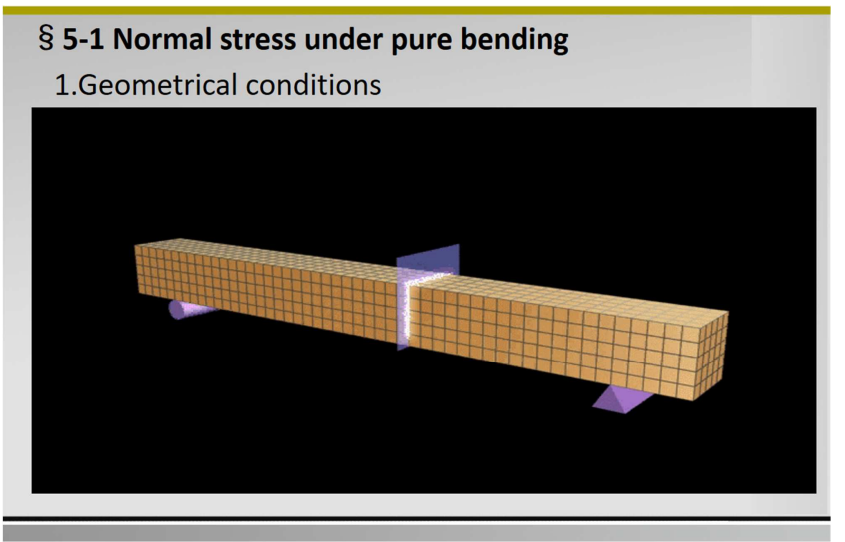

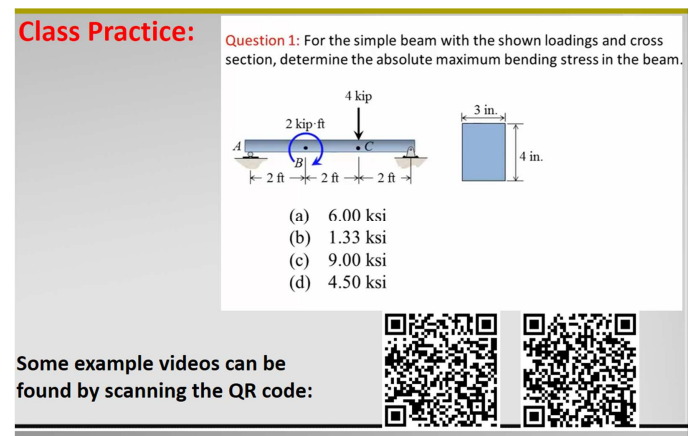

Figure 2. Some print screens of resource with $Q R$ code, animation.

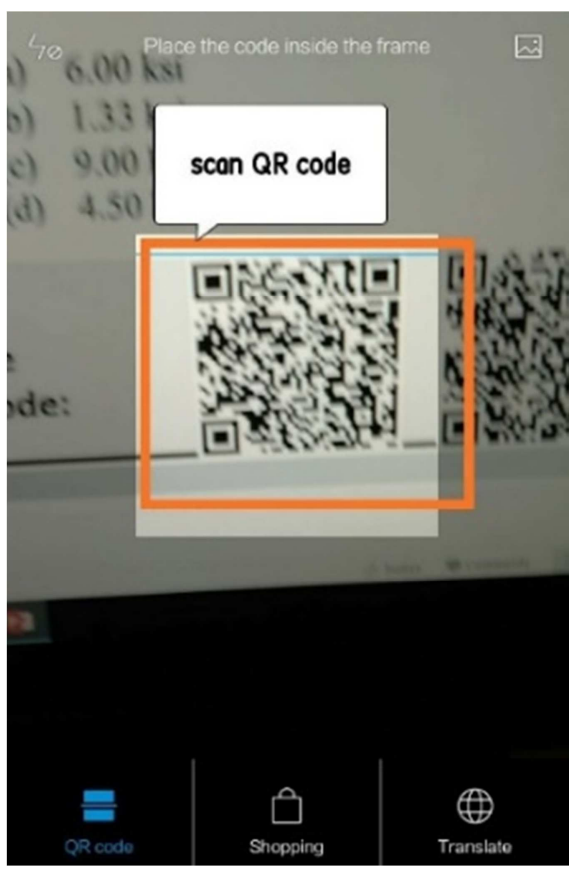

3:52 PM

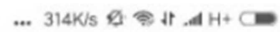

B Structural Analysis Simple Beam - Bendin

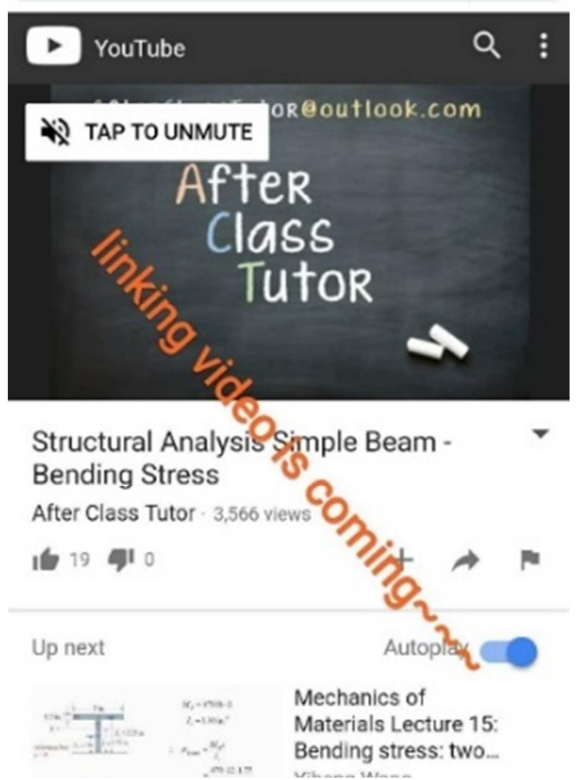

Figure 3. Scanning $Q R$ code to achieve relevant video by mobile phone accessing internet. 
Asynchronous online learning resource is another important means of representation. With the rapid popularity of portable electronic device with WAP function among college students, it becomes one fashion to learn by mobile phone. The number of online learners in postsecondary education is greatly increasing by a mobile device as their primary connection for class activities [16]. Moreover, Learners in online courses increasingly expect access to course materials, not only all of the time, but everywhere [17]. Simultaneously, research shows that provision of materials, even recordings, does not affect negatively on attendance [18]. Therefore, according to the main principle of UDL-multiple means of representation, developing asynchronous online learning resource will give learners an alternative way to acquire information and knowledge. On-line learning resource is not only suitable for students with learning disabilities such as mature students, but also fit for all the potential learners who are increasingly using mobile devices to connect to campus and to each other. Figure 4 shows the online learning resource linking with this module including message function for feedback. The online learning resource is developed based on WeChat APP that is the most popular and accessible APP in China. Therefore, there is almost no barriers for students to access it.

\section{$\times$ George2012 $\quad \vdots$ \\ Learning resource: Normal bending stress-mechanics of materials}

\section{8-04-09 Y.YUN George2012}

\author{
According to the UDL principle - multiple \\ means of representation should be \\ provided for the potential learners with \\ different learning preferences. This \\ online resource of normal bending stress \\ within mechanics of materails would be \\ uploaded here for learner utilization after \\ class, which includes Chinese version for \\ domestic students and English version \\ for international students or those who \\ tend to study abroad in the future.
}

\section{Learning resource in Chinese}

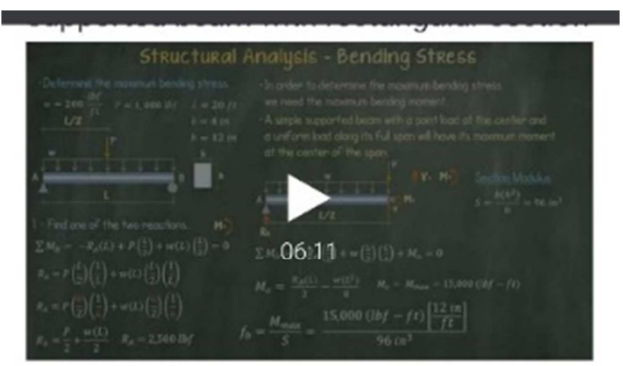

Video example instruction 2: I beam with symmetric cross section and $T$ beam with non-symmetric cross section
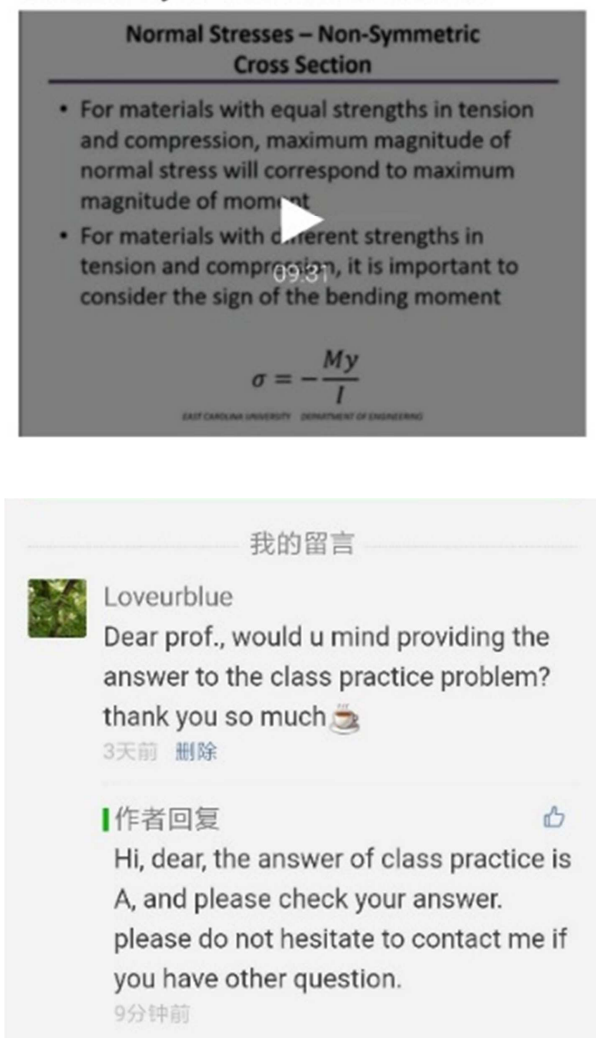

Figure 4. Print screens of online resource with videos, message feedback.

According to UDL theory, multiple means of representation have been provided for learners. Laborious oral explanations on some difficult points in module may be replaced by the more understandable animations or videos. In addition, the labor of lecturer in class will be alleviated, while the teaching effect will be increased.

\subsection{UDL and Students' Learning}

The learning resource designed according to UDL benefit students undoubtedly, as the possible barriers have been eliminated via different means of representation. In addition, alternative options of course assessment means are available for them according to their preferences, such as group collaboration plus presentation and so forth. Considering this course, group co-work plus presentation is regarded as one good means to assess students. Several studies have showed that collaboration among students can have a very positive 
impact both on student engagement and student retention (Elliot \& Decker, 1999; Goodsell Love, 1999; Lenning \& Ebbers, 1999, Tinto, 1998). By this novel assessment mean, students can not only study and practice more by group collaboration, but also they would be much more interested and confident in this module study. In addition, online discussion boards can be set up using the online learning environment and these can be a valuable tool for students who may not be able to attend campus outside of class hours.

Application of QR code linking resource makes relevant documents searching much easier and the novel technique motivate students to learn. Online feedback function bring them convenient communication with lecturers, and the interaction among lecturer and students individually may interest student to learn as the interactive student feels his feedback be focused on specially. Figure 5 shows student's learning by QR code and student-lecturer interaction after class by corresponding online feedback system.
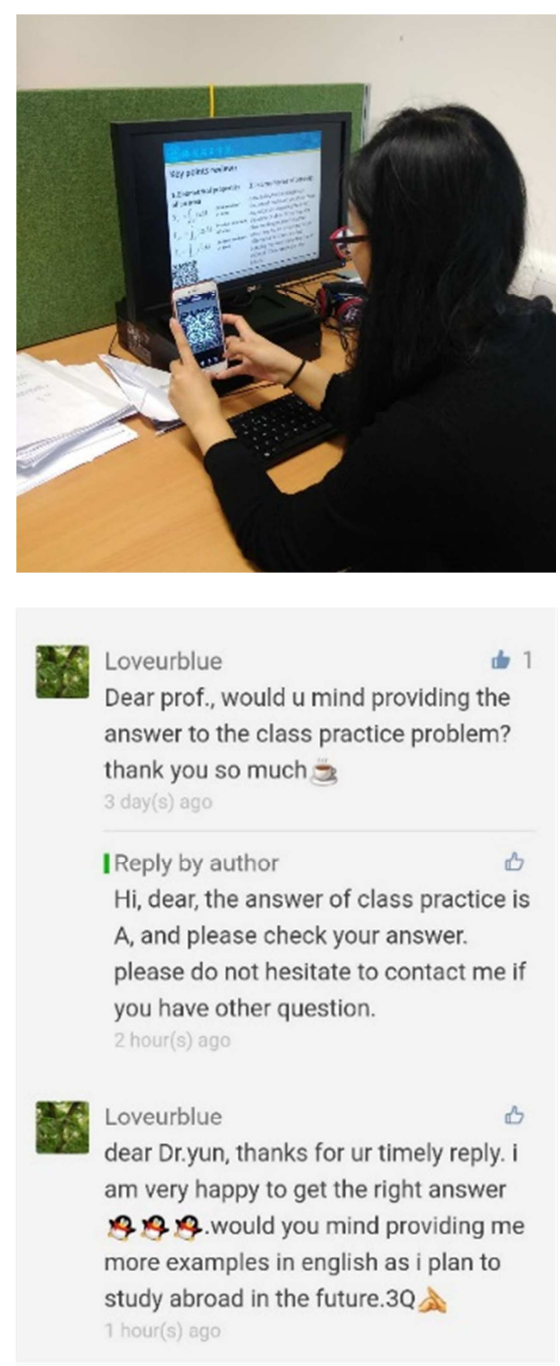

Figure 5. Picture of student's learning by $Q R$ code and print screen of student-lecturer interaction after class by online feedback system.

\subsection{Impact of UDL on Future Teaching Practice}

Before applying UDL principles, commonly the learning resource designed was not universal according to common student's level with average learning ability, which did not consider the special need of students whose learning ability are below the average level, not mention about learners with learning disabilities. Almost all the lecturers can manage to finish their teaching tasks according to the indicative syllabus routinely. However, there are attendants failing to pass the exam, more or less. However, little attention has been paid on this as the lecturers just simply thought that the cause of their failure was their own incorrect learning attitudes, or the unsuitable learning methods they utilized. Almost no lecturers thought to provide more accessible learning resources to students to improve their learning effect. That is not because they are stubborn but they did not realize that the style of learning resource might influence the learning effects so much.

As David Rose, one of the UDL's founders, has stated, "UDL puts the tag disabled where it belongs - on the curriculum, not the learner. The curriculum is disabled when it does not meet the needs of diverse learners" [19]. For the lecturers, what they should do is to make their lecture more accessible to diverse students including the students with learning disabilities. As relevant researches have demonstrated that application of UDL on higher education courses had a positive impact on students' academic performance $[6-8,20]$. Lecturers should integrate the UDL theory and spirits into their learning resource design and instructional design from the means of representation, expression and engagement. We can confidently believe that teaching effect of their courses will be much better than before, and their students are expected to benefit more from their improvement after applying UDL theory.

\section{Conclusions}

In this paper, UDL theory was integrated into the inclusive learning resource design via setting mechanics of materials as an example, which aims to make the learning resource more accessible to diverse learner so that the expected learning outcomes would be achieved for all potential learners. The main conclusions can be drawn below after learning resource design, practice, analysis and reflection.

(1). As the lecturers, integrating UDL theory into the whole teaching process including course syllabus, learning resource, class time and assessments will improve their teaching effects by multiple means of representation and expression. Moreover, laborious oral explanations on difficult contents may be replaced by the more understandable animations or videos and so forth.

(2). As the learners, the application of UDL in course resource design can provide alternative learning means satisfying diverse students with different learning preferences by utilizing novel techniques, attractive styles, appropriate assessment methods. Simultaneously, all these work can motivate learners to learn as well and finally promote them to be self-motivate learners.

(3). The proper application of UDL in learning resource 
design can improve the quality of talent training for Chinese higher education. Furthermore, graduate employment issues are supposed to be relieved as the graduates are much more competitive in job market after integrating UDL into their college study process.

\section{Future Research}

Rapid progress has been made in the past decades of years for Chinese higher education. According to the official data, the gross enrollment ratio of higher education was only $8.3 \%$ in 1996, and after about 20 years' development the enrollment ratio is up to $42.7 \%$ in 2016 [21]. In China, there are over 2,800 universities (including colleges, institutes) and more than 37 million registered college students in China although the enrollment rate of higher education is less than $50 \%$. For most of the Chinese universities, the heavily shortage of faculty in some disciplines results in the large-scale class even more than 200 students, which may rapidly decrease the instructional quality and learning effect [21]. How to integrated UDL theory into this large scale class is another key research orientation for higher education lecturers and researchers.

\section{Acknowledgements}

The work in this paper is one research production of project "Practice \& Research on Bilingual Education in Applied Talents Training Oriented Engineering Universities - A case study on civil engineering discipline of Luoyang Institute of Science and Technology" supported by The 13th Five-Year education science planning key project of Henan province (Project No. 2016-JKGHA-0062). And it is also funded by Bilingual Model Course Project of Luoyang Institute of Science and Technology. Their financial supports are sincerely appreciated.

\section{References}

[1] Center for Applied Special Technology. (2013). About UDL. Retrieved from http://www.udlcenter.org/aboutudl/whatisudl

[2] Rose, D. H., and Meyer, A. (2002). Teaching every student in the digital age: Universal Design for Learning. Alexandria, VA: Association for Supervision and Curriculum Development.

[3] Lieberman, L. J. (2017). The Need for Universal Design for Learning. Journal of Physical Education, Recreation \& Dance, 88(3), 5-7.

[4] Schelly, C. L., Davies, P. L., \& Spooner, C. L. (2011). Student Perceptions of Faculty Implementation of Universal Design for Learning. Journal of Postsecondary Education and Disability, 24(1), 17-28.

[5] Centre for Applied Special Technology. (2017) What is universal design for learning? Retrieved from http://www.cast.org/udl/index.html

[6] Burgstahler, S. E. (2015). Universal Design in Higher Education: From Principles to Practice. Harvard: Harvard
Education Press.

[7] Scott, S. S., McGuire, J. M., and Foley, T. E. (2003). Universal Design for Instruction: A Framework for Anticipating and Responding to Disability and Other Diverse Learning Needs in the College Classroom. Equity \& Excellence in Education. 36 (1), 40-49.

[8] Silver, P., Bourke, A., and Strehorn, K. C. (1998). Universal Instructional Design in Higher Education: An Approach for Inclusion. Equity \& Excellence. 31(2), 47-51.

[9] King-Sears, M. (2009). Universal Design for Learning: Technology and Pedagogy. Learning Disability Quarterly 32 (4), 199-201.

[10] Kortering, L. J., McClannon, T. W., and Braziel, P. M. (2008). Universal Design for Learning a Look at What Algebra and Biology Students with and without High Incidence Conditions Are Saying. Remedial and Special Education 29 (6), 352-363.

[11] Hoffman, B., \& Ritchie, D. C. (1998). Teaching and learning online: Tools, templates, and training. Technology and Teacher Educational Annual, 1998. [CD ROM]. Charlottesville, VA: Association for the Advancement of Computing in Education.

[12] Elliot, J. L., \& Decker, E. (1999). Garnering the fundamental resources for learning communities. In J. H. Levine (Ed.), Learning communities: New structures, new partnerships for learning (pp. 19-28). Columbia, SC: National Resource Center for the First-Year Experience and Students in Transition. University of South Carolina.

[13] Goodsell Love, A. (1999). What are learning communities? In J H. Levine (Ed.). Learning communities: New structures, new partnerships for learning. (pp. 1-8). Columbia, SC: National Resource Center for The First-Year Experience and Students in Transition. University of South Carolina.

[14] Lenning, O. T., \& Ebbers, L. H. (1999). The powerful potential of learning communities: Improving education for the future. ASHE-ERIC Higher Education Report, 26 (6). Washington D. C.: The George Washington School of Education and Human Development.

[15] Tinto, V. (1998). Colleges as communities: Taking research on student persistence seriously. Review of Higher Education, 21(2), 167-177.

[16] Chen, B., \& Denoyelles, A. (2013). Exploring students' mobile learning practices in higher education. EDUCAUSE Review, 48(5). Retrieved from https://er.educause.edu/articles/2013/10/exploring-students-m obile-learning-practices-in-higher-education

[17] Tobin, Thomas J. (2014) Increase Online Student Retention with Universal Design for Learning. Quarterly Review of Distance Education, 15(3), 13-24.

[18] Larkin, Helen E. (2010) "But they won't come to lectures..." The impact of audio recorded lectures on student experience and attendance." Australasian journal of educational technology 26(2), 238-249.

[19] Council for Exceptional Children. (2011, October 13). New guidelines for universal design for learning provide a roadmap for educators and educational publishers. Retrieved from http://www.cec.sped.org/AM/Template.cfm?Section=Home\& $\mathrm{CAT}=$ none $\&$ CONTENTID $=10573 \&$ TEMPLATE $=/ \mathrm{CM} /$ ContentDisplay.cfm. 
[20] Chen. S., \& Pei X. N. (2016). Cultivating expert learners in digital times-universal design for learning. E-education Research. (5), 58-65.
[21] Yun, Y. W. (2015). Research on bilingual teaching in civil engineering major of Henan higher education. Research in Teaching. 38(4), 87-90. 